\title{
Sorghum Drought Tolerance is Associated with Deeper Root System and Decreased Transpiration Rate
}

\author{
Gowsiga $S^{1}$., Djanaguiraman $\mathbf{M}^{1, *}$., Thavaprakaash $\mathbf{N}^{2}$., Jeyakumar $\mathbf{P}^{1}$. and Govindaraj $\mathbf{M}^{3,4, *}$ \\ 1 Department of Crop Physiology, Tamil Nadu Agricultural University, Coimbatore, Tamil Nadu 641003 , \\ India; gowsiga16@gmail.com (G.S.); jani@tnau.ac.in (D.M.); jeyakumar@tnau.ac.in (J.P) \\ 2 Department of Agronomy, Tamil Nadu Agricultural University, Coimbatore, \\ Tamil Nadu 641 003, India; thavaprakaash.n@tnau.ac.in (T.N) \\ 3 International Crops Research Institute for the Semi-Arid Tropics (ICRISAT), Patancheru-502 324, Telangana, \\ India; m.govindaraj@cgiar.org (M.G.) \\ 4 Alliance of Bioversity International and the International Center for Tropical Agriculture (CIAT), Cali, \\ Colombia \\ * Correspondence: jani@tnau.ac.in (D.M.); m.govindaraj@cgiar.org (M.G.)
}

\begin{abstract}
Drought decreases grain yield of sorghum [Sorghum bicolor (L.) Moench], and understanding the mechanism(s) related to drought tolerance is critical for sustaining sorghum production. Variation in root and shoot traits associated with drought tolerance were analyzed to provide an integrated view of factors that underlie the drought tolerance of sorghum. The plants were grown in the root column up to the five-leaf stage, then exposed to either 0.9 fraction of transpirable soil water (FTSW) or 0.4 FTSW for five days. In another experiment, at the five-leaf stage, stress was imposed for 14 days. Various root and shoot traits associated with drought tolerance were recorded. The seminal root angle of IS13540 was lower $\left(24.4^{\circ}\right)$ than IS23143 $\left(42.6^{\circ}\right)$. Drought stress increased the maximum root length $(40 \%)$ and total root length (58\%) of IS13540 than its irrigated control. In contrast, the maximum root length and total root length were decreased in IS23143. Similarly, across the lines, drought stress decreased stomatal conductance (37\%), transpiration rate $(42 \%)$, photosynthetic rate (40\%), photosystem II quantum yield (20\%), photochemical quenching (44\%), and total dry matter production $(34 \%)$ than irrigated control. An increased transpiration rate was observed in IS23143 than IS13540 under irrigated and drought stress. In IS23143, the reduction in photosynthetic rate under drought may be a combination of stomatal and non-stomatal factors. However, in IS13540, the reduction is especially by the stomatal factors. It is evident that IS13540 is a drought-tolerant line, and tolerance is related to a deep prolific root system and reduced transpiration rate.
\end{abstract}

Keywords: Deep root system; Photosynthetic rate; Root angle; Root length; Sorghum; Transpiration rate

\section{Introduction}

Sorghum [Sorghum bicolor (L.) Moench] is grown as a staple food crop by millions of people in Sub-Saharan Africa (SSA) and South Asian countries [1]. It is predicted that, in sorghum growing areas, the population will increase by 2.5 -fold by 2050 , and therefore, the demand for sorghum will increase by triple. Therefore, there is a greater reliance on cereal imports in those regions due to the lower current production level [1]. One of the reasons for lower grain yield is the coincidence of drought stress at critical growth stages of sorghum. Also, it is predicted that in the future, there will be a considerable variation in rainfall patterns in the sorghum growing areas [2], which could still cause a lower grain yield. Therefore, to achieve food security in the SSA, the grain yield of sorghum under drought stress has to be sustained, which could be possible by understanding the drought tolerance mechanism of sorghum.

The seedling and flowering stage drought tolerance of sorghum was associated with rooting depth, total length, and root conductivity [3-5]. Mace et al. [6] showed a positive 
relationship between the root angle and drought tolerance of sorghum. Genotypes with narrow root angles had a higher root length density at deeper soil depths at the seedling stage, enhancing drought tolerance [7]. Similarly, studies on winter wheat [Triticum aestivum (L.)] [8], upland rice [Oryza sativa (L.)] [9], and maize [Zea mays (L.)] [10] indicated that a deep and prolific root system is advantageous under drought stress. Besides deeper roots, higher root length density (RLD) at depth and low RLD at the surface are also considered as desired traits for drought tolerance [11]. In contrast, studies on rice [12], peanut (Arachis hypogaea L.) [13], and chickpea (Cicer arietinum L.) [14] showed that deep and profuse root system is not associated with drought tolerance. Also, it was demonstrated that a shallow, well-branched root system was associated with drought tolerance in spring wheat [8] and rice [15]. Hence, it can be hypothesized that an ideotype that increases the water uptake from deeper soil may not always yield higher under drought stress conditions.

Apart from root traits, stomatal closure is one of the earliest responses of the crop to drought stress [16-17]. Stomatal conductance and vapor pressure deficit (VPD) are the major drivers influencing transpiration rates [18]. A substantial amount of water can be lost from the leaves even when the stomata are at minimum aperture [19]. Furthermore, decreased stomatal conductance can affect the photosynthetic rate through reduced availability of $\mathrm{CO}_{2}$ to the enzyme Ribulose-1,5-bisphosphate carboxylase-oxygenase (RuBisCo), consequently lowering biomass [20]. Researches showed that the primary effect of drought was decreased photosynthetic rate through stomatal and non-stomatal limitations like damaging ultrastructure of chloroplast, RuBisCo regeneration, and carboxylation efficiency, inactivation of photosystem (PS) II reaction center, the maximum quantum yield of PS II ( $\mathrm{F}_{\mathrm{v}} / \mathrm{F}_{\mathrm{m}}$ ratio), electron transport rate (ETR), photochemical quenching (qP), leaf water potential, and osmotic adjustment [21-27].

In sorghum, the shoot and root traits associated with drought tolerance are studied independently. In this study, the various root traits like maximum root length, total root length, root diameter, and root: shoot ratio and shoot traits like transpiration rate, stomatal conductance, photosynthetic rate, and leaf photochemistry that can change under drought stress was quantified to understand the mechanism associated with drought tolerance of sorghum. This study fills a knowledge gap by recording the root architectural changes caused by drought stress and linking these with shoot traits related to transpiration and photosynthesis.

\section{Materials and Methods}

\subsection{Materials}

The sorghum lines IS13540 and IS23143 were selected based on our previous experiment [28]. The study indicated that under progressive soil drying, the line IS13540 had a lower transpiration rate than IS23143. 


\subsection{Measurement of root angle}

\subsubsection{Nodal root angle}

The seeds of IS13540 and IS23143 were surface sterilized using sodium hypochlorite $(10 \% \mathrm{v} / \mathrm{v})$ for $5 \mathrm{~min}$, followed by washing in deionized water for five times and sown in a plastic pot $(25.7 \times 25.5 \times 22.1 \mathrm{~cm}$; L x B X H) containing $9 \mathrm{~kg}$ of sandy clay loam soil. The pots had holes at the bottom for drainage. There were five replications for each line. In each pot, three seeds were sown at a depth of $3 \mathrm{~cm}$. After seedling emergence, the seedlings were thinned to one per pot. To each pot, 2 grams of urea, 1 gram of diammonium phosphate, and 1 gram of potash were added after thinning. The plants were irrigated on alternate days from emergence to 21 days after emergence (DAE). On the 22 $2^{\text {nd }}$ day, the soil was washed from the pot, and the roots were carefully removed with hand. The roots were washed with deionized water with hand to remove the debris and stone. The roots of the upper node are tough and thicker than the lower nodes, and the root angle remained in the original shape after removing soil and washing with water. The root angle of the first nodal root from the top of the plant was determined by measuring the root angle between the horizontal (i.e., soil surface) and the line along the slope of the nodal root at $2 \mathrm{~cm}$ from the root base using a protractor [29].

\subsubsection{Seminal root angle}

The seeds of IS13540 and IS23143 were surface-sterilized as described earlier, then germinated in a Petri plate ( $100 \mathrm{~mm} \times 15 \mathrm{~mm}$; diameter $\mathrm{x}$ thickness) using Whatman number 42 filter paper, moistened with $5 \mathrm{~mL}$ of deionized water for two days. In each Petri plate, ten seeds were placed. A $2 \%(w / v)$ agar (Type A; Sigma Chemicals, Bangalore, India) solution was prepared and autoclaved at standard temperature $\left(121^{\circ} \mathrm{C}\right)$ and pressure $\left(15 \mathrm{lbs} \mathrm{sq} \mathrm{inch}^{-1}\right)$ for $20 \mathrm{~min}$. Next, the sterilized agar was poured into the Petri plate $(12 \mathrm{x}$ $12 \times 1.7 \mathrm{~cm}$; $\mathrm{L} \times \mathrm{W} \times \mathrm{H}$ ) up to the rim under aseptic condition and allowed to solidify. Followed by this, all the sides of the Petri plates were sealed using clear cellophane tape (Amazon Basics Tape $1.9 \mathrm{~cm} \times 1605 \mathrm{~cm}$, Amazon, India). On the second day, a uniformly sized seedling (radicle length of $0.2-0.3 \mathrm{~cm}$ ) was selected and placed one per Petri plate containing agar in a vertical position with the radicle facing downwards through the cuts of the Petri plates. The Petri plates were positioned vertically in an incubation room maintained at $24.5 \pm 1.5^{\circ} \mathrm{C}$ for 14 days. There were five replications per line. On the $15^{\text {th }}$ day, the angle of the first pair of seminal roots was measured at a $3 \mathrm{~cm}$ distance from the seed relative to a vertical line passing through the stem base [30].

\subsection{Effects of vegetative stage drought stress: root column experiment}

2.3.1. Plant materials and crop husbandry

An outdoor experiment in a completely randomized block with a split plot treatment structure was conducted at the Department of Crop Physiology, Tamil Nadu Agricultural University, Coimbatore, $\left(11^{\circ} \mathrm{N} ; 77^{\circ} \mathrm{E} ; 426.7 \mathrm{~m} \mathrm{MSL}\right)$, India. Before starting the experiment, the clay-loamy soil was sieved through a $2 \mathrm{~mm}$ sieve, and the soil fraction that did not pass through the sieve was discarded. Next, the soil fraction $(<2 \mathrm{~mm})$ was sieved using a $1 \mathrm{~mm}$ sieve, and the fraction which passed through the sieve was collected. Finally, $5 \mathrm{~kg}$ of vermicompost was added to $200 \mathrm{~kg}$ of sieved soil and thoroughly mixed and filled in the column.

The soil was sampled to quantify the available soil moisture using a pressure plate apparatus [31]. Analysis indicated that the available soil moisture of the soil was $18 \pm 0.5 \%$. The soil $\mathrm{pH}$ and electrical conductivity were 7.7 and $0.32 \mathrm{dS} \mathrm{m}^{-1}$, respectively. The plant was grown in polyvinyl chloride (PVC) column $(100 \times 7.5 \mathrm{~cm}$; length $x$ inner diameter), and the bottom of the column had a plastic cap with a central hole of $1 \mathrm{~cm}$ diameter for drainage. Before sowing, each PVC column was filled with $6.5 \mathrm{~kg}$ of soil, and $2 \mathrm{~g}$ of urea, $2 \mathrm{~g}$ of diammonium phosphate, and $1 \mathrm{~g}$ of muriate of potash were added on top of the soil and mixed well. Then, the column was irrigated to $100 \%$ field capacity (FC). Three seeds 
of sorghum line (IS23143 or IS13540) were sown at $3 \mathrm{~cm}$ depth in each PVC column. After seedling emergence, the seedling was thinned to one and maintained till the completion of the experiment. The plants were irrigated daily in the evening up to FC. Plants were grown under the natural sunlit condition from sowing to the five-leaf stage (40 days after emergence; DAE). Afterward, the plants were divided into two groups; one served as irrigated control, and the other was drought stress.

\subsubsection{Imposition of drought stress}

The total transpirable soil water (TTSW) content was determined as the difference between the soil water content at FC and wilting point (WP). The FC and WP were determined through a pressure plate experiment, and, using FC and WP values, the fraction of transpirable soil water (FTSW) was calculated [FTSW $=$ (actual water content - water content at the wilting point) / TTSW] [32]. Drought stress was imposed by maintaining the plants at 0.4 FTSW, and the control plants were maintained at 0.9 FTSW.

At the five-leaf stage, all the plants were irrigated to FC, then the top of the column was completely covered with a PVC sheet by making a small slit. The slit was covered with white packing adhesive tape around plant collars such that there was no space between the plant and slit to minimize evaporative losses from the soil surface [33]. Then, the column weight was recorded in the morning (06:00 - 07:00 hours) to arrive at the weight corresponding to FC. The irrigated plants were weighed daily at 07:00 hours, and the quantity of water required to bring 0.9 FTSW was worked out and added. In the drought-stressed plants, the irrigation was withheld until the soil moisture dropped to 0.4 FTSW. At that point, the required quantity of water to maintain 0.4 FTSW was added. The plants were maintained at 0.9 or 0.4 FTSW for five days. Our previous study indicated that the FTSW reached a value of 0.3 on the $4^{\text {th }}$ day of progressive soil drying. At $0.3 \mathrm{FTSW}$, the photosynthetic rate and stomatal conductance were decreased by 70 and $81 \%$, respectively, from the initial value [28]. Apart from this, Gano et al. [5] reported that in sorghum, at 0.3 FTSW, the plants experienced drought stress as revealed by leaf rolling. Similarly, in this study, the plants at $0.4 \mathrm{FTSW}$ on the $2^{\text {nd }}$ day showed leaf rolling symptoms. Hence, the drought stress was imposed for five days.

The environmental condition during the drought stress period was presented in supplementary figure 1 . During the drought period, the daytime maximum temperature ranged between 37 and $38^{\circ} \mathrm{C}$ and the nighttime minimum temperature ranged from 22 to $23{ }^{\circ} \mathrm{C}$. Similarly, the daytime relative humidity ranged between 45 and $50 \%$ and nighttime humidity from 90 to $95 \%$. The plants were harvested after five days of drought stress.

\subsubsection{Traits recorded}

\subsubsection{Growth traits}

Plant height was measured as the distance from the soil surface to the tip of the fully expanded leaf and expressed as $\mathrm{cm}$. At harvest, the PVC column was gently tilted at about $80^{\circ}$, and water was flushed slowly to the bottom of the column. The wet loose soil was removed by hand so that the soil particle alone slipped out of the column. The entire root system was recovered and washed thrice in water by hand to remove any attached soil. The root system was laid on a flat surface and straightened to measure the maximum root length (rooting depth; measured from the base of the stem to the tip of the root) and expressed as $\mathrm{cm}$. Washed roots were stored in a plastic container containing $30 \%$ ethanol until further analysis [34].

The whole root system was cut into $30 \mathrm{~cm}$ long portions, and each part was carefully spread in a transparent tray $(20 \times 15 \times 2 \mathrm{~cm} ; \mathrm{L} \times \mathrm{W} \times \mathrm{H})$ containing water to minimize root overlap and scanned using an Epson photo scanner (Epson Perfection V800 with 100 dpi resolution, Epson, Long Beach, CA, USA). Images of scanned roots were analyzed using the WinRHIZO Pro image system (Regent Instruments, Inc., Quebec City, QC, Canada) to estimate total root length and root diameter as explained by McPhee [35] and Singh et al. 
[36]. The total root length and root diameter were expressed in $\mathrm{m}$ and $\mathrm{mm}$, respectively. Root length: shoot length ratio was calculated as the ratio of maximum root length to plant height [8, 37-38].

\subsubsection{Physiological measurements}

Plant transpiration rate was estimated on an hourly basis (from 08:00 to 15:00 hours) on all days of observation. The pigments, leaf area, canopy temperature, chlorophyll $a$ fluorescence kinetics, and gas exchange traits were recorded on the $5^{\text {th }}$ day of drought stress.

\subsection{Leaf area, chlorophyll index, and canopy temperature}

The chlorophyll index and canopy temperature were recorded on the attached tagged fully expanded top leaf from each replication between 10:00 and 14:00 hours in three replications. After harvest, the leaves were removed, and the leaf area was measured using a benchtop leaf area meter (LI-COR 3000; Lincoln, NE, USA) and expressed as $\mathrm{cm}^{2}$ plant ${ }^{-1}$. Chlorophyll index was measured using a chlorophyll meter [Soil Plant Analysis Development (SPAD); Model 502, Spectrum Technologies, Plainfield, IL, USA] and expressed as SPAD units. Canopy temperature was measured using an infrared camera (FLIR Systems, Inc., Wilsonville, OR, USA) and expressed as ${ }^{\circ} \mathrm{C}$.

\subsection{Chlorophyll $a$ fluorescence measurement}

The chlorophyll $a$ fluorescence traits were measured on attached tagged fully expanded top leaves on the $5^{\text {th }}$ day of drought stress using a modulated fluorometer (OS1p, Optisciences, Hudson, NH, USA). The chlorophyll $a$ fluorescence kinetics was measured in dark-adapted leaves using a dark adaptation clip. The leaves were continuously irradiated with white actinic light to measure the initial fluorescence in leaves acclimated to irradiation $\left(\mathrm{Fo}^{\prime}\right)$, steady-state fluorescence yield $\left(\mathrm{F}_{\mathrm{s}}\right)$, and maximum fluorescence yield (Fms) of irradiated leaves [39]. By using the above parameters, the following chlorophyll $a$ fluorescence parameters were calculated: effective quantum yield of PSII $\left[\phi\right.$ PSII $=\left(\mathrm{F}_{\mathrm{ms}}-\right.$ $\left.\mathrm{F}_{\mathrm{s}}\right) / \mathrm{F}_{\mathrm{ms}}$; apparent rate of photochemical transport of electrons through PSII (ETR $=\phi$ PSII $\times \mathrm{PAR} \times 0.5 \times 0.84)$, the coefficient of photochemical quenching $\left[\mathrm{qP}=\left(\mathrm{F}_{\mathrm{ms}}-\mathrm{F}_{\mathrm{s}}\right) /\left(\mathrm{Fms}_{\mathrm{ms}}-\mathrm{F}_{\mathrm{o}}\right)\right]$, and the coefficient of non-photochemical quenching of excitation energy $\left[\mathrm{NPQ}=\left(\mathrm{F}_{\mathrm{m}}\right.\right.$ $\mathrm{Fms} / \mathrm{Fms}_{\mathrm{ms}}$ by the instrument software [39-40].

\subsection{Photosynthetic rate, stomatal conductance, transpiration rate, and total dry matter production}

The leaf-level gas exchange measurements (photosynthesis, stomatal conductance, and transpiration rate) were measured on the tagged fully expanded top leaf using an LICOR 6400XT portable photosynthesis system (LI-COR, Lincoln, NE, USA). The gas exchange measurements were recorded at daytime growth temperature and ambient $\mathrm{CO}_{2}$ conditions (410 ppm). The internal light-emitting diode light source was set at $1600 \mu \mathrm{mol}$ $\mathrm{m}^{-2} \mathrm{~s}^{-1}$ to ensure a constant, uniform light across all measurements [41]. The total dry matter production was dried at $60^{\circ} \mathrm{C}$ for ten days and weighed and expressed as g plant ${ }^{-1}$.

\subsection{Effects of vegetative stage drought stress under field condition}

A field experiment was conducted in a split plot design with three replications. The main plot and sub-plots were irrigation regimes and lines, respectively. The main plot had two levels (1. Irrigated control: plants are irrigated at five-day intervals and 2. drought stress: withholding water for $15 \mathrm{~d}$ from $35 \mathrm{DAE}$ ). The sub plot had two levels (lines: 1 . IS13540 and 2. IS23143).

Sorghum lines were sown in a paired row method of planting $(60 / 30 \times 30 \mathrm{~cm})$ at a depth of $3 \mathrm{~cm}$. The fertilizer dose of 90:45:45 kg N:P $\mathrm{P}_{2} \mathrm{O}_{5}: \mathrm{K}_{2} \mathrm{O} \mathrm{ha}^{-1}$ was followed. The nitrogenous fertilizer was applied in two doses, one at sowing and another at $30 \mathrm{DAE}$. In 
addition, phosphorus and potassium fertilizers were added during sowing. The crop was irrigated once in five days until the five-leaf stage (35 DAE). After that, three irrigations were skipped for drought stress treatment from the five-leaf stage, and the plants were irrigated on $50 \mathrm{DAE}$. At the $5^{\text {th }}$ leaf stage, the primary stalk and the top fully expanded leaf were tagged to record the physiological traits. The weather parameters that prevailed during the drought stress period are presented in supplementary figure 2 .

\subsubsection{Traits recorded}

Physiological traits were recorded on the attached fully expanded top leaf from each replication between 10:00 and 14:00 hours on the $14^{\text {th }}$ day of withholding irrigation. The $\mathrm{F}_{\mathrm{v}} / \mathrm{Fm}_{\mathrm{m}}$ ratio and the performance index (PI $\mathrm{PBS}_{\mathrm{AS}}$ ) were measured through fast chlorophyll fluorescence induction kinetics as suggested by Strasser et al. [42]. Leaf-level gas exchange measurements (photosynthesis, stomatal conductance, and transpiration rate) were recorded on three replications using an LI-COR 6400XT portable photosynthesis system as described earlier. The total dry matter production was estimated by sampling five plants per replication after completion of drought stress, and the samples were dried at $60^{\circ} \mathrm{C}$ for ten days and weighed, and the average was expressed as g plant ${ }^{-1}$.

\section{Statistical Analyses}

The seminal and nodal root angles were analyzed using the PROC TTEST procedure of the SAS 9.3 version [43]. A $P$ value of $\leq 0.05$ was considered statistically significant. The root column experiment was designed in a completely randomized block with a split plot treatment structure with three replications $(n=3)$. The irrigation regime was the main plot factor, and the line was the sub plot factor. The PROC MIXED procedure of SAS was used for data analysis. The hourly transpiration data was analyzed by considering irrigation regime, line, days of observation, and time of observation (hourly transpiration rates) as fixed factors and block as a random factor. Results revealed that the trends of transpiration rate in both lines were similar for all days of observation. Therefore, the data were analyzed by combining days of observation by considering the irrigation regime, line, and time of observation as fixed factors and days of observation and block as random factors to get the overall effects of the irrigation regime and line. The data on leaf area, chlorophyll index, canopy temperature, $\mathrm{F}_{\mathrm{v}} / \mathrm{F}_{\mathrm{m}}$ ratio, chlorophyll $a$ kinetics, the photosynthetic rate, stomatal conductance, transpiration rate, and total dry matter production were analyzed by considering irrigation regime and lines as fixed factors and block as a random factor. The Tukey-Kramer adjustment was used to separate the treatment means. The field experiment was conducted in a split plot design with three replications. The main plot was the irrigation regime, and the sub plot was the line. The PROC MIXED procedure of SAS was used for data analysis as described earlier.

\section{Results}

\subsection{Nodal and seminal root angle $\left(^{\circ}\right)$}

The lines varied significantly $(P \leq 0.01)$ for nodal (Fig. 1a) and seminal root angle (Fig. $1 b)$. The nodal root angle was substantially higher in IS13540 $\left(59.4^{\circ}\right)$ than IS23143 $\left(41.4^{\circ}\right)$. In contrast, the seminal root angle was significantly lower in IS13540 $\left(24.4^{\circ}\right)$ than IS23143 $\left(42.6^{\circ}\right)$ (Fig. 1a-b). 


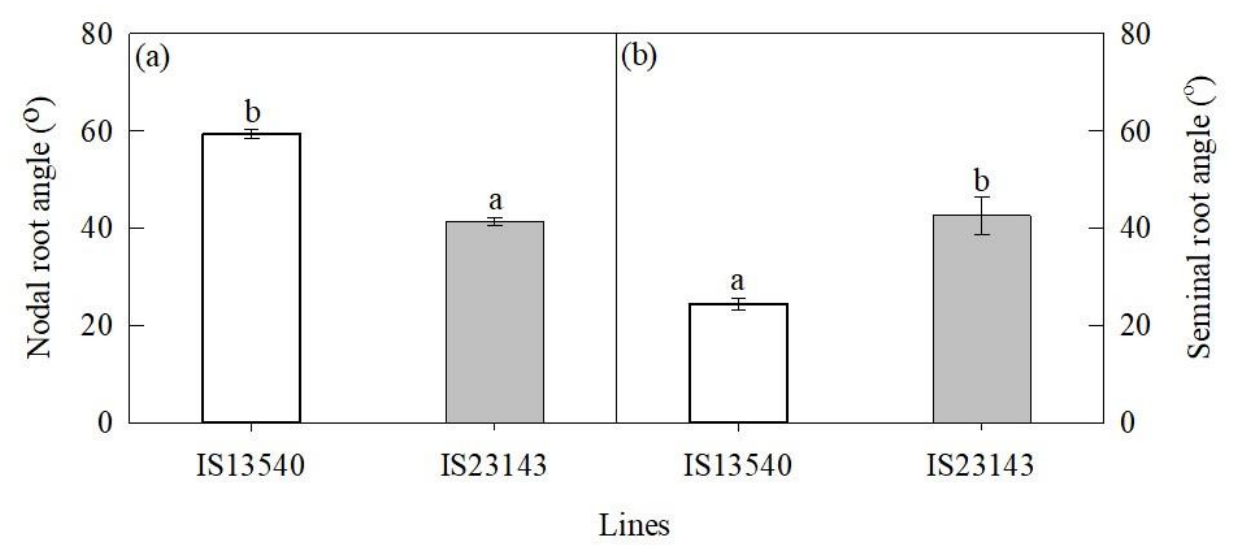

Figure 1. Variation in (a) nodal and (b) seminal root angle of sorghum line IS13540 and IS23143. Each datum is the mean \pm SEM of five replications $(n=5)$. Means with different letters are significantly different at $P \leq 0.05$.

\subsection{Effects of vegetative stage drought stress: root column experiment}

4.2.1. Maximum root length $\left(\mathrm{cm}\right.$ plant $\left.\mathrm{t}^{-1}\right)$, root length: shoot length ratio, total root length $\left(\mathrm{m}\right.$ plant $\left.{ }^{-1}\right)$, and average root diameter $(\mathrm{mm})$

The effect of the line was significant for maximum root length $(P \leq 0.05)$ and total root length $(P \leq 0.01)$ (Fig. 2a, 2c), and the effect of the irrigation regime was significant $(P \leq 0.01)$ for maximum root length (Fig. 2a) and root length: shoot length ratio (Fig. 2b). However, there were significant $(P \leq 0.001)$ effects of the interaction of lines and irrigation regime for maximum root length, root length: shoot length ratio, average root diameter, and total root length (Fig. 2a-d).

Differential response for maximum root length and root length: shoot length ratio was observed between the lines (Fig. 2a-b). The line IS23143 had a higher maximum root length and root length: shoot length ratio under irrigated conditions than drought stress. However, the line IS13540 had a higher maximum root length and root length: shoot length ratio under drought than irrigated control. Between the lines, IS13540 had an increased total root length (58\%) under drought than irrigated control. However, there was no difference between drought and irrigated conditions for total root length in IS23143 (Fig. 2c). The average root diameter of IS13540 was higher under drought than other treatment combinations (Fig. 2d).

\subsubsection{Hourly transpiration rate $\left(\mathrm{g} \mathrm{h}^{-1}\right.$ plant $\left.^{-1}\right)$}

The rate of transpiration varied significantly $(P \leq 0.05)$ for line, irrigation regime, and their interactions from 8:00 to 15:00 hours (Fig. 3). Under the irrigated condition, the highest transpiration rate was observed around 12:00 to 13:00 hours (Fig. 3). However, under drought stress, the highest transpiration rate was observed from 10:00 to 10:30 hours. Irrespective of the time of the observation, IS23143 had an increased transpiration rate than IS13540. Within each line, the irrigated plants had a higher transpiration rate than drought-stressed plants (Fig. 3). 


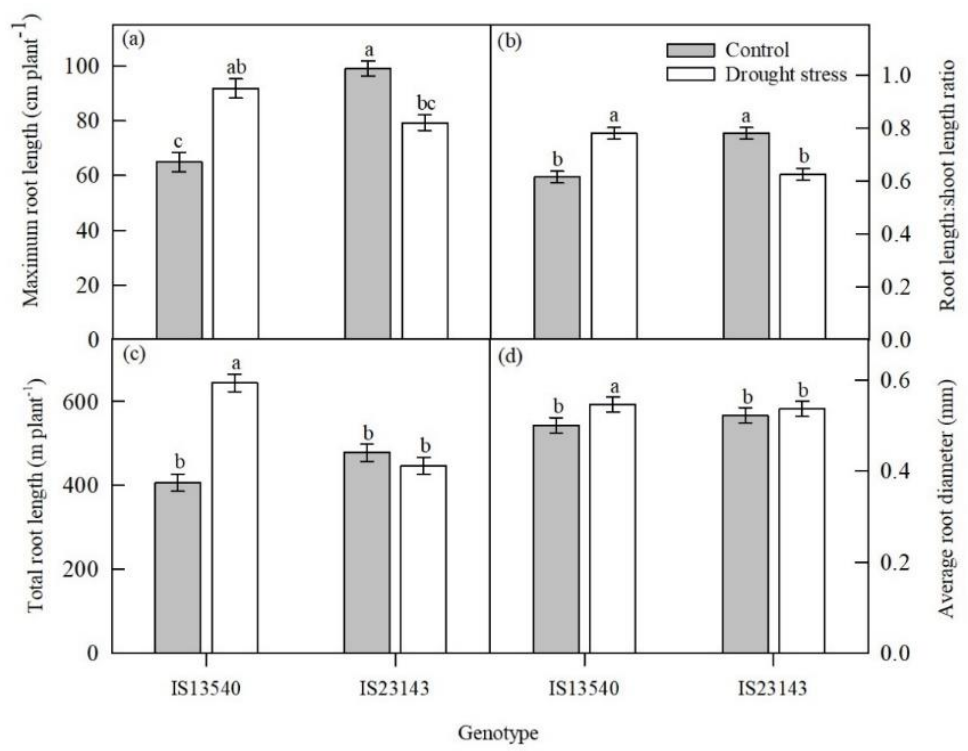

Figure 2. Interaction effect of drought and lines on (a) maximum root length ( $\left.\mathrm{cm} \mathrm{plant}^{-1}\right)$, (b) root length: shoot length ratio, (c) total root length $\left(\mathrm{m}\right.$ plant $\left.\mathrm{t}^{-1}\right)$, and $(\mathrm{d})$ average root diameter $(\mathrm{mm})$ in sorghum lines. Each datum is the mean \pm SEM of three plants $(n=3)$. Means with different letters are significantly different at $P \leq 0.05$.
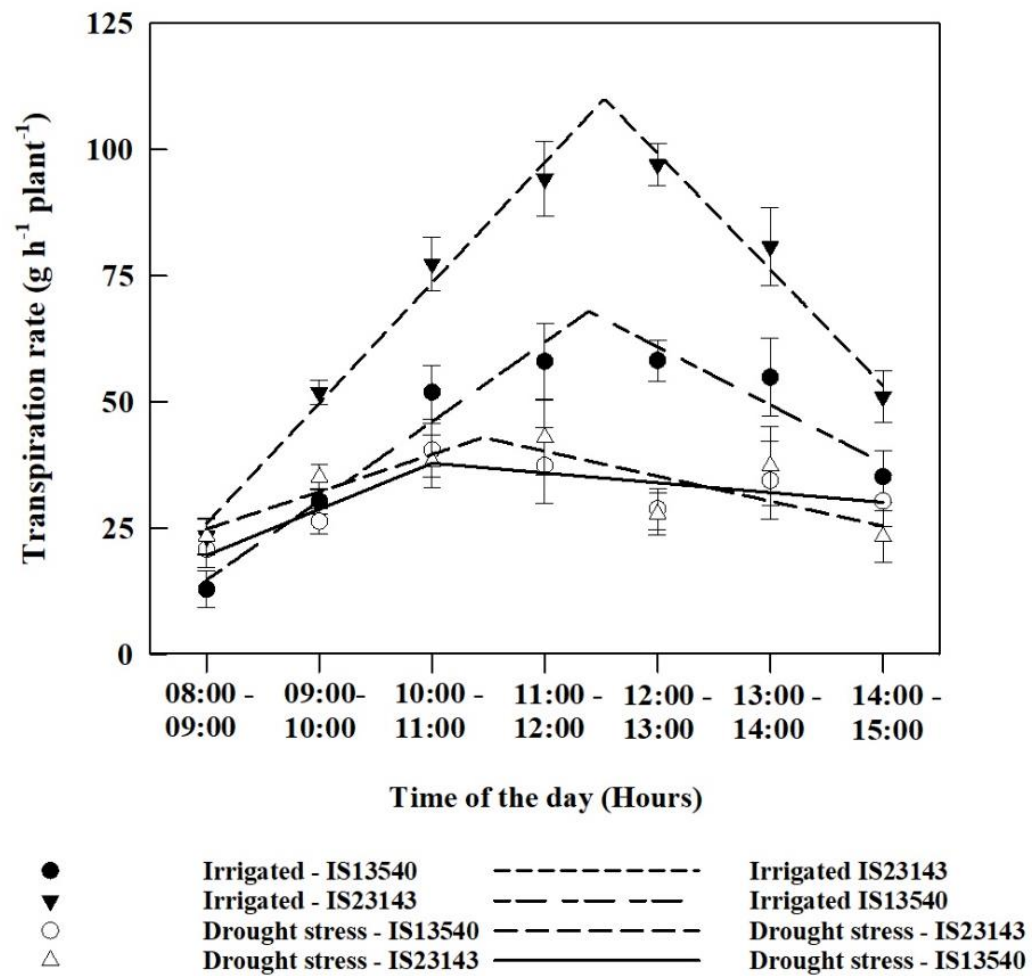

Figure 3. Interaction effect of irrigation regime and line on transpiration rate $\left(\mathrm{g} \mathrm{h}^{-1} \mathrm{plant}^{-1}\right)$ of IS13540 and IS23143 from 08:00 to 15:00 hours. Each datum is the mean \pm SEM of three plants $(n=3)$.

4.2.3. Leaf area, chlorophyll, canopy temperature, and chlorophyll $a$ fluorescence traits [chlorophyll index (SPAD units), leaf area $\left(\mathrm{cm}^{2}\right.$ plant $\left.{ }^{-1}\right)$, canopy temperature $\left({ }^{\circ} \mathrm{C}\right), \mathrm{F}_{\mathrm{v}} / \mathrm{F}_{\mathrm{m}}$ ratio (relative units), $\phi$ PSII (no units), $\mathrm{qP}$ (no units), ETR ( $\mu \mathrm{mol}$ electron $\mathrm{m}^{-2} \mathrm{~s}^{-1}$ ), and NPQ (no units)] 
There were significant differences $(P \leq 0.05)$ between lines, irrigation regime, and their interaction on leaf area, canopy temperature, and $\mathrm{F}_{\mathrm{v}} / \mathrm{F}_{\mathrm{m}}$ ratio (Fig. $4 \mathrm{~b}-\mathrm{d}$ ). However, the chlorophyll index varied significantly $(P \leq 0.05)$ for drought stress alone (Fig. $4 \mathrm{a})$. In both lines, drought stress decreased the chlorophyll index (Fig. 4a). The leaf area of IS23143 decreased significantly $(P \leq 0.01)$ under drought stress compared to irrigated control; however, there was no significant difference between irrigated and drought stress for IS13540 (Fig. 4b). Between the lines, drought stress increased the canopy temperature (Fig. 4c) and decreased $F_{v} / F_{m}$ ratio (Fig. $4 d$ ). The highest decrease in $F_{v} / F_{m}$ ratio was observed in IS23143, along with the lowest canopy temperature increase under drought (Fig. 4c-d).

Between the irrigation regime, drought stress significantly $(P \leq 0.05)$ decreased the $\phi P S I I, q P$, and ETR. In contrast, the NPQ was increased by drought stress (Fig. 4e-h). Between the lines, IS13540 had a higher $\phi$ PSII, qP, and ETR than IS23143 under drought stress. However, there were no differences between the lines on chlorophyll $a$ fluorescence traits under the irrigated condition (Fig. 4e, f, h). In addition, the NPQ level was significantly lower in IS13540 than IS23143 under both irrigated and drought stress conditions (Fig. 4g).

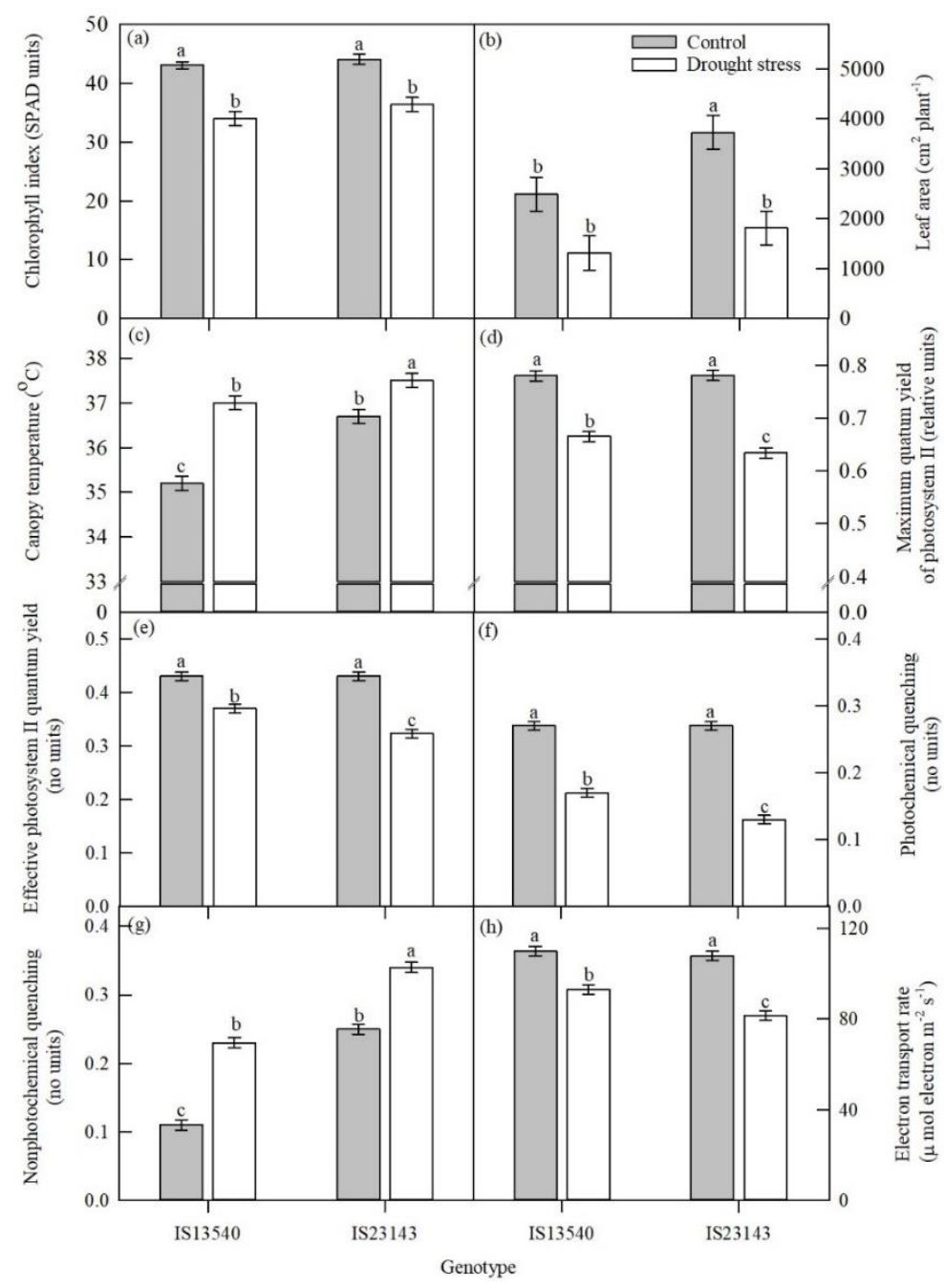

Figure 4. Interaction effect of irrigation regime and line on (a) chlorophyll index (SPAD units), (b) leaf area ( $\mathrm{cm}^{2}$ plant$\left.{ }^{1}\right)$, (c) canopy temperature $\left({ }^{\circ} \mathrm{C}\right),(\mathrm{d}) \mathrm{Fv}_{\mathrm{v}} / \mathrm{F}_{\mathrm{m}}$ ratio (relative units), (e) $\phi \mathrm{PSII}$ (no units), (f) qP (no units), (g) NPQ (no units), and $(\mathrm{h})$ ETR $\left(\mu \mathrm{mol}\right.$ electron $\left.{ }^{-1} \mathrm{~m}^{-2} \mathrm{~s}^{-1}\right)$ in sorghum lines. Each datum is the mean \pm SEM of three plants $(\mathrm{n}=3)$. Means with different letters are significantly different at $P \leq 0.05$. 
4.2.4. Photosynthetic rate $\left(\mu \mathrm{mol} \mathrm{m} \mathrm{s}^{-2} \mathrm{~s}^{-1}\right)$, stomatal conductance $\left(\mathrm{mol} \mathrm{m}^{-2} \mathrm{~s}^{-1}\right)$, transpiration rate $\left(\mathrm{mmol} \mathrm{m}^{-2} \mathrm{~s}^{-1}\right)$, and total dry matter production $\left(\mathrm{g} \mathrm{plant}^{-1}\right)$

Line, irrigation regime, and interaction of line and irrigation regime varied significantly $(P \leq 0.05)$ for photosynthetic rate, stomatal conductance, transpiration rate, and total dry matter production (Fig. 5a-d). Drought stress significantly $(P \leq 0.05)$ decreased photosynthetic rate than irrigated control, and between the lines, IS13540 had a higher photosynthetic rate than IS23143 under drought stress (Fig. 5a). The stomatal conductance and transpiration rate was decreased under drought stress than irrigated control (Fig. 5b, c), and the line IS13540 had lower stomatal conductance and transpiration rate than IS23143. In contrast, the total dry matter production was the highest in IS13540 under drought stress compared to IS23143 (Fig. 5d).

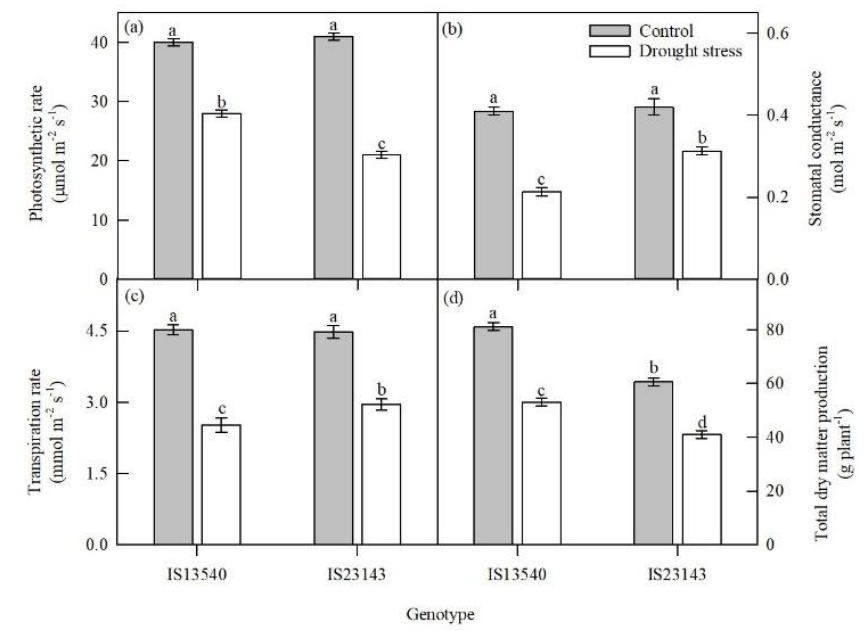

Figure 5. Interaction effect of irrigation regime and lines on (a) photosynthetic rate ( $\left.\mu \mathrm{mol} \mathrm{m}^{-2} \mathrm{~s}^{-1}\right)$, (b) stomatal conductance $\left(\mathrm{mol} \mathrm{m}^{-2} \mathrm{~s}^{-1}\right),(\mathrm{c})$ transpiration rate $\left(\mathrm{mmol} \mathrm{m}^{-2} \mathrm{~s}^{-1}\right)$, and (d) total dry matter production $\left(\mathrm{g} \mathrm{plant}^{-1}\right)$ in sorghum. Each datum is the mean \pm SEM of three plants $(\mathrm{n}=3)$. Means with different letters are significantly different at $P \leq 0.05$.

\subsection{Effects of vegetative stage drought stress under field condition}

4.3.1. Chlorophyll index (SPAD units) and leaf area $\left(\mathrm{cm}^{2}\right.$ plant $\left.{ }^{-1}\right)$

The chlorophyll index and leaf area varied significantly $(P \leq 0.01)$ for lines and irrigation regimes (Table 1). Between the irrigation regime, drought stress decreased chlorophyll index $(9.5 \%)$ and leaf area plant ${ }^{-1}(21 \%)$ compared to irrigated control (Table 1). Similarly, between the lines, IS23143 had a higher leaf area (12\%) than IS13540. In contrast, the chlorophyll index was lower (7\%) in IS23143 than in IS13540 (Table 1).

Table 1. Main effects of lines and drought stress on chlorophyll index (SPAD units) and leaf area $\left(\mathrm{cm}^{2}\right.$ plant-1) in sorghum lines exposed to drought stress at vegetative stage.

\begin{tabular}{llllll}
\hline \multirow{2}{*}{ Trait } & \multicolumn{2}{l}{ Lines } & & \multicolumn{2}{l}{ Moisture regimes } \\
\cline { 2 - 3 } \cline { 6 - 7 } & IS13540 & IS23143 & & Irrigated & Drought stress \\
\hline Chlorophyll index (SPAD units) & $47.8 \pm 0.816^{\mathrm{a}}$ & $44.4 \pm 0.816^{\mathrm{b}}$ & & $48.4 \pm 0.816^{\mathrm{A}}$ & $43.8 \pm 0.816^{\mathrm{B}}$ \\
Leaf area $\left(\mathrm{cm}^{2}\right.$ plant $\left.^{-1}\right)$ & $561.6 \pm 13.5^{\mathrm{b}}$ & $644.7 \pm 13.5^{\mathrm{a}}$ & & $675.5 \pm 13.5^{\mathrm{A}}$ & $530.5 \pm 13.5^{\mathrm{B}}$ \\
\hline
\end{tabular}

tThe means with different letters between lines (lowercase letter) or drought stress (capital letter) are significantly different at $P \leq 0.5(\mathrm{n}=6)$.

4.3.2. Chlorophyll a fluorescence and gas exchange traits $\left[\mathrm{F}_{\mathrm{v}} / \mathrm{F}_{\mathrm{m}}\right.$ ratio and $\mathrm{PI}_{\mathrm{ABS}}$ (relative units), photosynthetic rate $\left(\mu \mathrm{mol} \mathrm{m}^{-2} \mathrm{~s}^{-1}\right)$, stomatal conductance $\left(\mathrm{mol} \mathrm{m}^{-2} \mathrm{~s}^{-1}\right)$, transpiration rate $\left(\mathrm{mmol} \mathrm{m}^{-2} \mathrm{~s}^{-1}\right)$, and total dry matter production $\left(\mathrm{g} \mathrm{plant}^{-1}\right)$ ] 
There were significant $(P \leq 0.01)$ differences in $\mathrm{F}_{\mathrm{v}} / \mathrm{F}_{\mathrm{m}}$ ratio and $\mathrm{PI}_{\mathrm{ABS}}$ for lines, drought stress, and the interactions of lines and drought stress (Fig. 6a-b). In both the lines, drought stress significantly $(P \leq 0.01)$ decreased $\mathrm{F}_{\mathrm{v}} / \mathrm{F}_{\mathrm{m}}$ ratio and PI $\mathrm{ABS}_{\mathrm{BS}}$ compared to irrigated condition; however, the decrease was higher in IS23143 than IS13540 (Fig. 6a-b).

The photosynthetic rate, stomatal conductance, transpiration rate, and total dry matter production were significant $(P \leq 0.01)$ for lines, moisture regimes, and their interactions (Fig. 6c-f). A higher decrease in photosynthetic rate and total dry matter production was observed in IS23143 under drought stress than IS13540 (Fig. 6c, 6e, 6f). In contrast, the line IS23143 had a higher transpiration rate and stomatal conductance under drought stress than IS13540 (Fig. 6d, e).

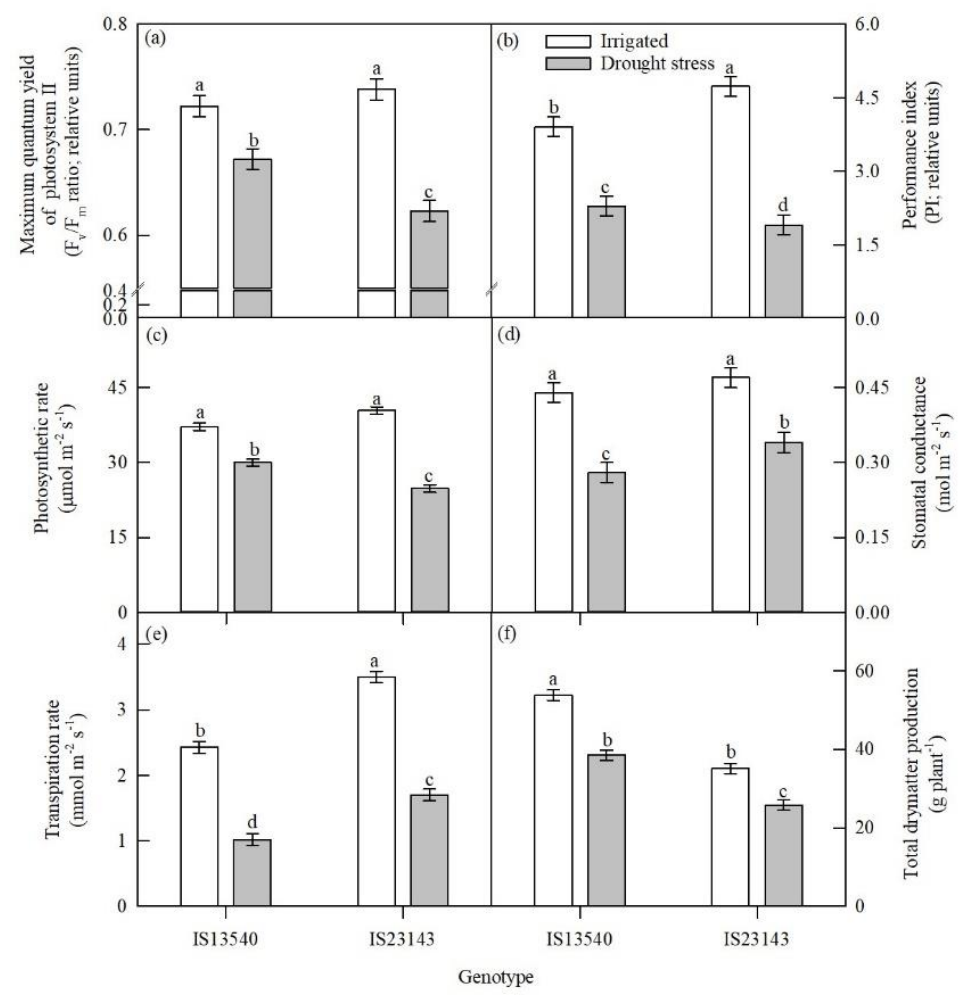

Figure 6. Interaction effect of irrigation regime and lines on (a) $F_{v} / F_{m}$ ratio (relative units), (b) PIABs (relative units), (c) photosynthetic rate $\left(\mu \mathrm{mol} \mathrm{m}^{-2} \mathrm{~s}^{-1}\right),(\mathrm{d})$ stomatal conductance $\left(\mathrm{mol} \mathrm{m}^{-2} \mathrm{~s}^{-1}\right),(\mathrm{e})$ transpiration rate $(\mathrm{mmol}$ $\left.\mathrm{m}^{-2} \mathrm{~s}^{-1}\right)$, and (f) total dry matter production $\left(\mathrm{g} \mathrm{plant}^{-1}\right)$ in sorghum lines. Each datum is the mean \pm SEM of three plants $(\mathrm{n}=3)$. Means with different letters are significantly different at $P \leq 0.05$.

\section{Discussion}

Drought is important abiotic stress, limiting sorghum yield in arid and semi-arid regions [44]. The root architecture and stomatal conductance are the essential traits associated with drought tolerance under limited soil moisture because roots maintain water uptake [45], and stomatal conductance regulates transpiration rate [46]. Hence, targeting root architecture and stomatal conductance can be a better approach for improving the drought tolerance of sorghum [47-49].

The profuse and deep root systems are generally considered drought-tolerant traits. Deep rooting is a complex trait governed by a narrow root angle and higher maximum root length $[9,29,50]$. The present study confirmed the above findings, evidenced by a higher maximum root length, root length: shoot length ratio under drought stress, and a narrow seminal root angle $\left(\sim 25^{\circ}\right)$ in the line IS13540 compared to IS23143. Apart from maximum root length, the line IS13540 had a higher total root length than IS23143, showing that this line can extract more water from deep soil layers, provided moisture was 
present in deeper soil horizons $[38,51]$. The deep rooting of IS13540 could be associated with narrow root angle [9], greater root penetration rate ability [52], achieved by large root diameter [53]. This has been confirmed in rice, wheat, and maize, as deep rooting with profuse branching was associated with drought tolerance [9, 30, 54-55].

Previous studies have reported strong coordination between below-ground and above-ground morphological changes under drought stress [56-57]. In general, drought avoidance in plants is achieved by maintaining turgor through increased water absorption from deeper soils through increased rooting depth and/or reduction in water loss through decreased leaf area and stomatal conductance under drought stress [48-49, 58-59]. These findings indicate that both root and shoot system traits are involved in the drought tolerance of sorghum. In line with these, the genotype IS13540 had a deeper and more extensive root system, decreased transpiration rate under drought stress (Fig. 2a, 2c, 4b, and 5c).

Genotypes with deep and prolific root systems under drought stress would be advantageous if the size of the shoot were smaller that consumed less water [60]. Under drought stress, compared to IS23143, the line IS13540 had a lower transpiration rate due to decreased stomatal conductance. The relationship between root length and stomatal conductance was explained by Fraccasso et al. [61], namely, the sorghum lines with higher root: shoot ratio also reduced stomatal conductance and transpiration rate under drought, as observed in the present study. The above changes explain the water saver mechanism of drought tolerance.

The decrease in photosynthetic rate under drought stress may be due to stomatal and/or non-stomatal factors. Chlorophyll pigment is involved in capturing light energy, and a reduction in chlorophyll content under drought could be associated with damage to the chloroplast structure [62-63]. Between the lines, IS13540 had a higher chlorophyll content than IS23143, indicating a comparatively higher drought tolerance ability of IS13540 than IS23143. Between the lines, IS23143 had a lower increase in canopy temperature than IS13540 under drought stress, indicating that this line had a higher transpiration rate. This was validated in the hourly transpiration rate from 8:00 hours to 15:00 hours. In the IS13540 line, the reduction in photosynthetic rate under drought stress was associated with stomatal factor alone, as evidenced by a higher decrease in stomatal conductance (48\%) than $\phi$ PSII $(11 \%)$ and ETR $(8 \%)$ compared to its irrigated control [64]. In contrast, in IS23143, the decrease in photosynthetic rate is a combination of both stomatal and non-stomatal factors [65], as demonstrated by an equal reduction in stomatal conductance $(25 \%), \phi$ PSII $(24 \%)$, and ETR (25\%) compared to its irrigated control. The above findings indicate that the line IS13540 had better tolerance to drought stress than IS23143.

The decrease in $\mathrm{F}_{\mathrm{v}} / \mathrm{F}_{\mathrm{m}}$ ratio under drought stress may be associated with an increase in $F_{o}$ value. The rise in $F_{o}$ value under drought stress indicates the inactivation of reaction centers [66], photoinhibition, and damage of PS II [67-68]. The decrease in qP (Fig. 4f) and $\phi$ PSII (Fig. 4e) and increase in NPQ values (Fig. 4g) under drought than irrigated control suggest that the photosynthetic electron transport activity decreases under drought (Fig. $4 \mathrm{~h})$. Therefore, more light energy has to be dissipated as heat through non-photochemical pathways [69]. The performance index (PI) represents the energy flow efficiency of photosynthetic electron transport beyond PSII [70]. A higher value of PI under drought stress was recorded in IS13540 than IS23143, indicating its efficient electron transport rate (Fig. $6 \mathrm{~b})$. The above trait might have contributed to IS13540 per se performance under drought conditions. 


\section{Conclusions}

The major conclusions from this study are (i) drought stress increased maximum root length, root length: shoot length ratio, total root length, and decreased the photosynthetic rate, stomatal conductance, transpiration rate, $\phi$ PSII, photochemical quenching, and electron transport rate and total dry matter production of sorghum, (ii) under both irrigated and drought stress, a decreased transpiration rate, and increased photosynthetic rate was observed in IS13540 than IS23143, (iii) the decrease in the photosynthetic rate under drought stress in IS13540, was mainly associated with stomatal factors, and in IS23143 it was associated with both stomatal and non-stomatal factors, and (iv) the drought tolerance ability of IS13540 is associated with a deep root system and decreased transpiration rate.

Author Contributions: Conducted laboratory, glasshouse, and field experiment, G.S.; Conceptualization, monitored the experiments data curation, written, editing and review M.D. and G.M.; edited the manuscript and followed up with field experiment T.N.; edited the manuscript and followed up with experiments J.P; and editing the manuscript and review G.M.

\section{Funding:}

This research was supported by the International Crops Research Institute for the Semi-Arid Tropics (ICRISAT), Patancheru - 502 324, Telangana, India. Sub-project title: Root System Architecture and Its Association with Yield under Limited Water Regimes in Diverse Sorghum Lines (2020-2021).

Institutional Review Board Statement: Not applicable.

Informed Consent Statement: Not applicable.

Data Availability Statement: Raw data available from the author upon request

Conflicts of Interest: The author declares no conflict of interest.

\section{References}

1. van-Ittersum, M. K.; van Bussel, L.G.J.; Wolf, J.; Grassini, P.; van Wart, J.; Guilpart, N.; Claessens, L.; de Groot, H.; Wiebe, K.; Mason-D'Croz, D.; Yang, H.; Boogaard, H.; van Oort, P.A.J.; van Loon, M.P.; Saito, K.; Adimo, O.; Adjei-Nsiah, S.; Agali, A.; Bala, A.; Chikowo, R.; Kaizzi, K.; Kouressy, M.; Makoi, J.H.J.R.; Ouattara, K.; Tesfaye, K.; Cassman, K.G., Can sub-Saharan Africa feed itself? Proc. Natl. Acad. Sci. U.S.A. 2016, 113 (52), 1496414969.

2. IPCC. Climate Change 2021: The Physical Science Basis. Contribution of Working Group I to the Sixth Assessment Report of the Intergovernmental Panel on Climate Change [Masson-Delmotte, V.; P. Zhai; A. Pirani; S. L. Connors; C. Pean; S. Berger; N. Caud; Y. Chen; L. Goldfarb; M. I. Gomis; M. Huang; K. Leitzell; E. Lonnoy; J. B. R. Matthews; T. K. Maycock; T. Waterfield; O. Yelekçi; R. Yu; and B. Zhou (eds.)]. Cambridge University Press. In-Press. 2021.

3. Matsuura, A.; Inanaga, S.; Sugimoto, Y., Mechanism of interspecific differences among four gramineous crops in growth response to soil drying. Japanese J. Crop. Sci. 1996, 65 (2), 352-360.

4. Tsuji, W.; Inanaga, S.; Araki, H.; Morita, S.; An, P.; Sonobe, K., Development and distribution of root system in two grain sorghum cultivars originated from Sudan under drought stress. J. Plant Prod. Sci. 2005, 8 (5), 553-562.

5. Gano, B.; Dembele, J.S.B.; Tovignan, T.K.; Sine, B.; Vadez, V.; Diouf, D.; Audebert, A., Adaptation responses to early drought stress of West Africa sorghum varieties. Agron. 2021, 11, 443.

6. Mace, E.S.; Singh, V.; Van Oosterom, E. J.; Hammer, G.L.; Hunt, C.H.; Jordan, D.R., QTL for nodal root angle in sorghum (Sorghum bicolor L. Moench) co-locate with QTL for traits associated with drought adaptation. Theor. Appl. Genet. 2012, 124 (1), 97-109.

7. Liang, X.; Erickson, J.E.; Vermerris, W.; Rowland, D.L.; Sollenberger, L.E.; Silveira, M.L., Root architecture of sorghum genotypes differing in root angles under different water regimes. J. Crop Improv. 2017, 31 (1), 39-55. 
8. Djanaguiraman, M.; Prasad, P.V.V.; Kumari, J.; Rengel, Z. Root length and root lipid composition contribute to drought tolerance of winter and spring wheat. Plant Soil 2019, 439 (1), 57-73.

9. Uga, Y.; Sugimoto, K.; Ogawa, S.; Rane, J.; Ishitani, M.; Hara, N.; Kitomi, Y.; Inukai, Y.; Ono, K.; Kanno, N.; Inoue, H.; Takehisa, H.; Motoyama, R.; Nagamura, Y.; Wu, J.; Matsumoto, T.; Takai, T.; Okuno, K.; Yano, M. Control of root system architecture by DEEPER ROOTING 1 increases rice yield under drought conditions. Nat. Genet. 2013, 45 (9), 1097-1102.

10. Hammer, G.L.; Dong, Z.S.; McLean, G.; Doherty, A.; Messina, C.; Schusler, J.; Zinselmeier, C.; Paszkiewicz, S.; Cooper, M. Can changes in canopy and/or root system architecture explain historical maize yield trends in the US corn belt? Crop Sci. 2009, 49, 299-312.

11. Passioura, J.B. The role of root system characteristics in the drought resistance of crop plants. 1982. In: Drought Resistance in Crops with Emphasis on Rice. Pp. 71-82. International Rice Research Institute: Los Banos, Philippines.

12. Price, A.H.; Cairns, J.E.; Horton, P.; Jones, H.G.; Griffiths, H. Linking drought-resistance mechanisms to drought avoidance in upland rice using a QTL approach: progress and new opportunities to integrate stomatal and mesophyll responses. J. Exp. Bot. 2002, 53 (371), 989-1004.

13. Ratnakumar, P.; Vadez, V. Groundnut (Arachis hypogaea) genotypes tolerant to intermittent drought maintain a high harvest index and have small leaf canopy under stress. Funct. Plant Biol. 2011, 38 (12), 1016-1023.

14. Zaman-Allah, M.; Jenkinson, D.M.; Vadez, V., A conservative pattern of water use, rather than deep or profuse rooting, is critical for the terminal drought tolerance of chickpea. J. Exp. Bot. 2011, 62 (12), 4239-4252.

15. Tahere, A.-S.; Yamauchi, A.; Kamoshita, A.;Wade, L.J. Genotypic variation in response of rainfed lowland rice to drought and rewatering: II. Root growth. J. Plant Prod. Sci. 2000, 3, 180-188.

16. Rosenthal, W.D.; Arkin, G.F.; Shouse, P.J.; Jordan, W.R. Water deficit effects on transpiration and leaf growth I. Agronomy J. 1987, 79 (6), 1019-1026.

17. Wang, C.; He, J.; Zhao, T.-H.; Cao, Y.; Wang, G.; Sun, B.; Yan, X.; Guo, W.; Li, M.-H. The smaller the leaf is, the faster the leaf water loses in a temperate forest. Front. Plant Sci. 2019, 10 (58).

18. Geetika, G.; van Oosterom, E.J.; George-Jaeggli, B.; Mortlock, M.Y.; Deifel, K.S.; McLean, G.; Hammer, G.L., Genotypic variation in whole-plant transpiration efficiency in sorghum only partly aligns with variation in stomatal conductance. Funct. Plant Biol. 2019, 46 (12), 1072-1089.

19. Muchow, R.C.; Sinclair, T.R. Epidermal conductance, stomatal density and stomatal size among genotypes of Sorghum bicolor (L.) Moench. Plant Cell Environ. 1989, 12 (4), 425-431.

20. Hajihashemi, S. Stomatal regulation as a drought-tolerance mechanism. 2019. In: Roychoudhury, A., Tripathi, D. (eds) Molecular Plant Abiotic Stress. Wiley Publisher, New Jersey, USA, pp 45-64.

21. Bjorkman, O.; Demmig, B., Photon yield of $\mathrm{O}_{2}$ evolution and chlorophyll fluorescence characteristics at $77 \mathrm{~K}$ among vascular plants of diverse origins. Planta 1987, 170 (4), 489-504.

22. Farooq, M.; Wahid, A.; Kobayashi, N.; Fujita, D.; Basra, S.M.A., Plant drought stress: effects, mechanisms and management. Agron. Sustain. Dev. 2009, 29 (1), 185-212.

23. Escalona, J.M.; Flexas, J.; Medrano, H., Stomatal and non-stomatal limitations of photosynthesis under water stress in field-grown grapevines. Funct. Plant Biol. 1999, 26 (5), 421-433.

24. Li, G.L.; Wu, H.X.; Sun, Y.Q.; Zhang, S.Y., Response of chlorophyll fluorescence parameters to drought stress in sugar beet seedlings. Russ. J. Plant Physiol. 2013, 60 (3), 337-342.

25. Golding, A. J.; Johnson, G.N. Down-regulation of linear and activation of cyclic electron transport during drought. Planta 2003, 218 (1), 107-14.

26. Blum, A.; Osmotic adjustment is a prime drought stress adaptive engine in support of plant production. Plant Cell Environ. 2017, 40 (1), 4-10.

27. Chen, H.; Jiang, J.-G.G., Osmotic adjustment and plant adaptation to environmental changes related to drought and salinity. Environ. Rev. 2010, 18, 309-319.

28. Gowsiga, S.; Djanaguiraman, M.; Thavaprakaash, N.; Jeyakumar, P.; Govindaraj, M., Effects of progressive soil drying on sorghum leaf physiology. Pharma Innovation 2021, 10(5):110-115.

29. Ali, M.L.; Luetchens, J.; Nascimento, J.H.B.d.; Shaver, T.M.; Kruger, G.R.; Lorenz, A.J., Genetic variation in seminal and nodal root angle and their association with grain yield of maize under water-stressed field conditions. Plant Soil 2015, 397, 213-225.

30. Manschadi, A.M.; Christopher, J.; deVoil, P.; Hammer, G.L., The role of root architectural traits in adaptation of wheat to water-limited environments. Funct. Plant Biol. 2006, 33 (9), 823-837. 
31. Richards, L.; A pressure-membrane extraction apparatus for soil solution. Soil Sci. 1941, 51 (5), $377-386$.

32. Sinclair, T.R.; Ludlow, M.M., Influence of soil water supply on the plant water balance of four tropical grain legumes. Funct. Plant Biol. 1986, 13 (3), 329-341.

33. Fracasso, A.; Trindade, L.; Amaducci, S. Drought tolerance strategies highlighted by two Sorghum bicolor races in a dry-down experiment. J. Plant Physiol. 2016, 190, 1-14.

34. Fenta, B.A.; Beebe, S.E.; Kunert, K.J.; Burridge, J.D.; Barlow, K.M.; Lynch, J.P.; Foyer, C.H. Field phenotyping of soybean roots for drought stress tolerance. Agron. 2014, 4 (3), 418-435.

35. McPhee K.; Variation for seedling root architecture in the core collection of pea germplasm. Crop Sci. 2005, 45, 1758-1763.

36. Singh, V.; van Oosterom, E.J.; Jordan, D.R.; Hunt, C.H.; Hammer, G.L., Genetic variability and control of nodal root angle in sorghum. Crop Sci. 2011, 51 (5), 2011-2020.

37. Tomar, R.S.S.; Tiwari, S.; Vinod-Naik, B.K.; Chand, S.; Deshmukh, R.; Mallick, N.; Singh, S.; Singh, N.K.; Tomar, S.M.S. Molecular and morpho-agronomical characterization of root architecture at seedling and reproductive stages for drought tolerance in wheat. PLoS One 2016, 11(6), e0156528.

38. Djanaguiraman, M.; Prasad, P.V.V.; Kumari, J.; Sehgal, S.K.; Friebe, B.; Djalovic, I.; Chen, Y.; Siddique, K.H.M.; Gill, B.S. Alien chromosome segment from Aegilops speltoides and Dasypyrum villosum increases drought tolerance in wheat via profuse and deep root system. BMC Plant Biol. 2019, 19 (1), 242.

39. Van-Kooten, O.; Snel, J., The use of chlorophyll fluorescence nomenclature in plant stress physiology. Photosyn. Res. 1990, 25, 147-50.

40. Maxwell, K.; Johnson, G.N. Chlorophyll fluorescence--a practical guide. J. Exp. Bot. 2000, 51 (345), $659-668$.

41. Djanaguiraman, M.; Prasad, P.V.V.; Murugan, M.; Perumal, R.; Reddy, U.K., Physiological differences among sorghum (Sorghum bicolor L. Moench) genotypes under high temperature stress. Environ. Exp. Bot. 2014, 100, 4354.

42. Strasser, R.J.; Srivastava, A.; Govindjee. Polyphasic chlorophyll a fluorescence transient in plants and cyanobacteria. Photochem. Photobiol. 1995, 61 (1), 32-42.

43. SAS Institute, 2003. The SAS Users Guide Version 9.1. SAS Institute, Cary, NC.

44. Zandalinas, S.I.; Fritschi, F.B.; Mittler, R. Global warming, climate change, and environmental pollution: recipe for a multifactorial stress combination disaster. Trends Plant Sci. 2021, 26 (6), 588-599.

45. Aroca, R.; Ruiz-Lozano, J. M., Regulation of Root Water Uptake Under Drought Stress Conditions. In Plant Responses to Drought Stress: From Morphological to Molecular Features, Aroca, R., Ed. Springer Berlin Heidelberg: Berlin, Heidelberg, 2012; pp 113-127.

46. Beebe, S.E.; Rao, I.M.; Blair, M.W.; Acosta-Gallegos, J.A., Phenotyping common beans for adaptation to drought. Front. Physiol. 2013, 4, 35-35.

47. Vadez, V.; Deshpande, S.P.; Kholova, J.; Hammer, G.L.; Borrell, A.; Talwar, H.; Hash, C.T., Jr. Stay-green quantitative trait loci's effects on water extraction, transpiration efficiency and seed yield depend on recipient parent background. Funct. Plant Biol. 2011, 38, 553-566

48. Sofi, P.A.; Djanaguiraman, M.; Siddique, K.H.M.; Prasad, P.V.V. Reproductive fitness in common bean (Phaseolus vulgaris L.) under drought stress is associated with root length and volume. Indian J. Plant Physiol. 2018, 23 (4), 796-809.

49. Sofi, P.A.; Rehman, K.; Gull, M.; Kumari, J.; Djanaguiraman, M.; Prasad, P.V.V. Integrating root architecture and physiological approaches for improving drought tolerance in common bean (Phaseolus vulgaris L.). Plant Physiol. Reports 2021, 26 (1), 4-22.

50. Trachsel, S.; Kaeppler, S.M.; Brown, K.M.; Lynch, J.P., Maize root growth angles become steeper under low N conditions. Field Crops Res. 2013, 140, 18-31.

51. Trachsel, S.; Kaeppler, S.M.; Brown, K.M.; Lynch, J.P. Shovelomics: High throughput phenotyping of maize (Zea mays L.) root architecture in the field. Plant Soil 2011, 341, 75-87.

52. Kirkegaard, J.; Lilley, J., Root penetration rate - a benchmark to identify soil and plant limitations to rooting depth in wheat. Aust. J. Exp. Agric. 2007, 47 (5), 590-602.

53. Clark, L.J.; Whalley, W.R.; Barraclough, P.B. How do roots penetrate strong soil? Plant Soil 2003,255 (1), $93-104$.

54. Wasson, A.P.; Richards, R.A.; Chatrath, R.; Misra, S.C.; Prasad, S.V.S.; Rebetzke, G.J.; Kirkegaard, J.A.; Christopher, J.; Watt, M. Traits and selection strategies to improve root systems and water uptake in water-limited wheat crops. J. Exp. Bot. 2012, 63 (9), 3485-3498. 
55. Comas, L.; Becker, S.; Cruz, V.M.; Byrne, P.F.; Dierig, D.A., Root traits contributing to plant productivity under drought. Front. Plant Sci. 2013, 4, 442.

56. Yoshida, S.; Bhattacharjee, D.P.; Cabuslay, G.S., Relationship between plant type and root growth in rice. Soil Sci. Plant Nutr. 1982, 28 (4), 473-482.

57. Xu, W.; Cui, K.; Xu, A.; Nie, L.; Huang, J.; Peng, S. Drought stress condition increases root to shoot ratio via alteration of carbohydrate partitioning and enzymatic activity in rice seedlings. Acta Physiol. Plant. 2015, 37 (2), 9.

58. Saradadevi, R.; Palta, J.A.; Siddique, K.H.M. ABA-mediated stomatal response in regulating water use during the development of terminal drought in wheat. Front. Plant Sci. 2017, 8 (1251).

59. Munns, R.; Sharp, R. Involvement of abscisic acid in controlling plant growth in soil of low water potential. Funct. Plant Biol. 1993, 20 (5), 425-437.

60. Vadez, V.; Kholova, J.; Zaman-Allah, M.; Belko, N. Water: the most important 'molecular' component of water stress tolerance research. Funct. Plant Biol. 2013, 40 (12), 1310-1322.

61. Fracasso, A.; Trindade, L.M.; Amaducci, S., Drought stress tolerance strategies revealed by RNA-Seq in two sorghum genotypes with contrasting WUE. BMC Plant Biology 2016, 16 (1), 115.

62. Bolat, I.; Dikilitas, M.; Ercisli, S.; Ikinci, A.; Tonkaz, T., The effect of water stress on some morphological, physiological, and biochemical characteristics and bud success on apple and quince rootstocks. Sci. World J. 2014, 769-732.

63. Zhang, Y.-B.; Yang, S.-L.; Dao, J.-M.; Deng, J.; Shahzad, A. N.; Fan, X.; Li, R.-D.; Quan, Y.-J.; Bukhari, S.A.H.; Zeng, Z.-H. Drought-induced alterations in photosynthetic, ultrastructural and biochemical traits of contrasting sugarcane genotypes. PLos One 2020, 15 (7), e0235845.

64. Flexas, J.; Bota, J.; Loreto, F.; Cornic, G.; Sharkey, T.D. Diffusive and metabolic limitations to photosynthesis under drought and salinity in $\mathrm{C}_{3}$ plants. Plant Biol. 2004, 6, 269-279.

65. Farquhar, G.D.; Sharkey, T.D. Stomatal conductance and photosynthesis. Ann. Rev. Plant Physiol. 1982, 33 (1), 317-345.

66. Wang, Z.X.; Chen, L.; Ai, J.; Qin, H.Y.; Liu, Y.X.; Xu, P.L.; Jiao, Z.Q.; Zhao, Y.; Zhang, Q.T. Photosynthesis and activity of photosystem II in response to drought stress in Amur Grape (Vitis amurensis Rupr.). Photosynthetica 2012, 50, 189-196.

67. Huang, C.; Zhao, S.; Wang, L.; Anjum, S.A.; Chen, M.; Zhou, H.; Zou, C., Alteration in chlorophyll fluorescence, lipid peroxidation and antioxidant enzymes activities in hybrid ramie (Boehmeria nivea L.) under drought stress. Aust. J. Crop Sci. 2013, 7, 594-599.

68. Xu, Q.; Ma, X.; Lv, T.; Bai, M.; Wang, Z.; Niu, J., Effects of water stress on fluorescence parameters and photosynthetic characteristics of drip irrigation in rice. Water 2020, 12 (1), 289.

69. Ruban, A.V. Non-photochemical chlorophyll fluorescence quenching: Mechanism and effectiveness in protecting plants from photodamage. Plant Physiol. 2016, 170 (4), 1903-1916.

70. Yusuf, M.A.; Kumar, D.; Rajwanshi, R.; Strasser, R. J.; Tsimilli-Michael, M.; Govindjee; Sarin, N.B. Overexpression of $\gamma$-tocopherol methyl transferase gene in transgenic Brassica juncea plants alleviates abiotic stress: Physiological and chlorophyll a fluorescence measurements. Biochim. Biophys. Acta Bioenerg (BBA) - Bioenergetics 2010, 1797 (8), 1428-1438. 